\title{
Spectrum of Spinal Dysraphism in Pediatric Patients in a Tertiary Care Hospital
}

\author{
Musawer Khan ${ }^{1}$, Arif Hussain ${ }^{2}$, Huma Gul', Ambreen Syed ${ }^{4}$ \\ ${ }^{1}$ Department of Neurosurgery, MTI Mardan Medical Complex, ${ }^{3}$ District Headquarters Hospital, Mardan \\ ${ }^{2}$ Department of Neurosurgery, MTI Lady Reading Hospital, ${ }^{4}$ Hayatabad Medical Complex, Peshawar - \\ Pakistan.
}

\section{ABSTRACT}

Objectives: To report the spectrum of spinal dysraphism presenting in pediatric patients admitted to the Department of Neurosurgery Lady reading hospital Peshawar.

Material \& Methods: A descriptive case series was conducted and total of 89 patients (age between 2 months to 12 years) were included who underwent the surgical treatment. All patients were examined for clinical and radiological diagnosis of spinal dysraphism.

Results: The average age at treatment was $23 \pm 39.77$ months. The most recurring (52.8\%) presenting symptom was the swelling on the back followed by lower limb weakness. Meningocele was reported in $11.2 \%$, myelomeningocele in $47.2 \%$, myelomeningocele $\&$ hydrocephalus in $12.4 \%$, tethered cord syndrome in $25.8 \%$, and diastematomyelia $3.4 \%$ of patients. Excision combined with the repair was done in $58.4 \%$, release $\&$ repair done in $29.2 \%$ and endoscopic third ventriculostomy/ventriculoperitoneal shunts with the repair were done in $12.4 \%$ patients. Cerebrospinal fluid leak was reported in $3.7 \%$, wound infection in $4.5 \%$ and mortality was reported in $3.4 \%$ patients.

Conclusion: Overall, a good outcome was reported in the majority of our patients. Surgical procedures like myelomeningocele's excision \& repair, tethered cord's release \& repair, and ETV/VP shunt in patients with hydrocephalus can lead to satisfactory clinical outcomes.

Keywords: Spinal Dysraphism, Endoscopic third Ventriculostomy (ETV), Ventriculoperitoneal (VP) Shunt, Myelocoele, Myelomeningocele, Tethered Cord Syndrome (TCS), Diastematomyelia.

\section{Corresponding Author: Musawer Khan}

Department of Neurosurgery, Mardan Medical Complex MTI, Mardan - Pakistan

Email: modestgaze@yahoo.com

\section{Date of Submission: 31-05-2021}

Date of Revision: 25-06-2021

Date of Online Publishing: 13-06-2021

Date of Print: 30-06-2021
DOI: $10.36552 /$ pjns.v25i2.548

\section{INTRODUCTION}

Spinal dysraphism (SD) is an umbrella term ${ }^{1}$ that describes a heterogeneous group of developmental abnormalities of the spine and 
spinal cord due to the neural tube's defective closure. Spinal dysraphism disorders lead to neurological, orthopedic, and urological dysfunctions. ${ }^{2}$ The incidence of spinal dysraphism is generally estimated to around 0.05 to 0.25 / 1000 live births. When spina bifida occulta (bone cleft lesions in the lower lumbar spinous processes) is included, the incidence rises to $20 \%$ for the whole population. ${ }^{3}$ In another study on spinal dysraphism, the incidence was reported as $1-3 / 1000$ live births. ${ }^{4}$ Spinal dysraphism requires a multidisciplinary approach to address the complex nature of the disease and its symptoms. Patients can have varying degrees of outcome and many factors are responsible for this. ${ }^{5}$ Of the many doctors and auxiliary staff, the role of neurosurgeon could be of paramount importance in the amelioration of patients suffering from spinal dysraphism. ${ }^{6}$ We conducted this case series to report the spectrum of spinal dysraphism presenting in pediatric patients from a hospital in Peshawar, Pakistan.

In diastematomyelia, two hemicords clinically present with scoliosis and tethered-cord syndrome. A tuft of hair at the back is a distinctive feature on physical examination. The fibrous septum divides the cord into two hemi cords. In type 1, cartilage separates the two hemicords, which have their own dural tube wrapping them individually. In type 2, a fibrous septum separates the hemi-cords wrapped in a single dural sleeve. ${ }^{7}$ The cause of myelomeningoceles and myeloceles is the defect in the closure of the primary neural tube. The latter is rare in occurrence. Most cases reported are usually the myelomeningocele (98\%). The position of the neural placode relative to the skin surface of the skin makes it a differentiating feature between the two. Chiari II malformation and myelomeningocele often coexist. Tethered cord syndrome (TCS) usually brings up symptoms during a growth spurt. On imaging, TCS strictly refers to patients with a lowlying cord and thickened filum (> 1.5mm). ${ }^{7}$ Patients generally show no symptoms and have no signs of tethered cord. Generally, the repaired cases of myelomeningocele have an unnoticed tethering of the cord. Early and prompt treatment can reverse the deterioration. A better way to ensure a timely intervention by a team of specialized doctors and auxiliary staff is to address the problems of such children in a spina bifida clinic where things can be discussed and implemented as decided by the board. ${ }^{8}$ Typical symptoms of tethered cord/SD involve the pain of the back and lower limb in most cases. Others are related to Orthopedic and urological symptoms that include hip dislocations, club feet, and higharched feet. Urodynamic disturbances are present in almost all pediatric patients of myelomeningocele. ${ }^{8}$ The typical presentation is a lumbar cutaneous defect, enuresis, unexplained back or leg pain, foot deformities, leg length discrepancies or scoliosis. ${ }^{9}$

Common and major six signs and symptoms seen in the pediatric population with TCS include weakness (55\%), gait problems (54\%), spinal scoliosis (51\%), limb pain (32\%), skeletal deformities (11\%), and urological dysfunction (6\%). ${ }^{10}$ Open dysraphisms are seen at birth with skin-deficient, midline, swelling over the back. Hydrocephalus is not uncommon. There is a CSF leak leading to meningitis. Also, common is Arnold chiari malformation. Closed dysraphisms often present as skin-covered mass at the back or with neurocutaneous markers like increased hair growth, tail-like appendages, hemangioma, skin tag, or dermal sinuses. ${ }^{1}$ The clinical features of spinal dysraphism can be midline lumbosacral cutaneous hemangiomas, a tuft of hair, the dermal sinus, subcutaneous lipoma or skin appendages. $^{11}$ Radicular pain, weakness, spasticity, hyporeflexia, sensory problems, and bladder dysfunctioning have been reported in up to $75 \%$ of patients who present with tethered cord syndrome (TCS). ${ }^{12}$ Regional anomalies or malformations in the early or late developmental period can also have an association with spinal dysraphism. Associated with spinal dysraphism 
are cloacal exstrophy, thickening of filum terminale, anorectal anomalies, and lipomas of the caudal part of the spinal cord. Sometimes the only presenting feature of dysraphism is scoliosis. $^{2}$

\section{MATERIAL AND METHODS}

\section{Study Type \& Setting}

A descriptive case series was conducted from January 2017 to January 2019 at the Department of Neurosurgery, Lady Reading Hospital, Peshawar. Total 89 patients with informed consent from the parents/attendants were included in the study that underwent surgical treatment. Prior ethical approval of the study was taken from the institutional review board committee.

\section{Inclusion Criteria}

Child patients of both genders were included from age between 2 months to 12 years. All cases of spinal dysraphism were included which admitted through outpatient department (OPD) as elective cases.

\section{Exclusion Criteria}

Patients excluded who were not fit for surgery. All re-do cases, rupture, and emergency cases were excluded. Patients excluded who were not willing for surgery.

\section{Clinical \& Radiological Assessments}

All patients were examined for clinical and radiological diagnosis of spinal dysraphism. Data were collected on patients' age, gender, presenting symptoms, a surgical procedure performed, complications reported, and the outcome (Good/poor). The outcome was assessed after surgery. Complications (CSF leak and wound infection) and mortality occurring after surgery were regarded as poor outcome while others were having good outcome. The clinical information and the scans were included through informed consent from the attendants of the patients.

\section{Surgical Procedure}

All patients underwent surgical treatment. The surgical procedures mainly followed were the excision and repair, release and repair, endoscopic third ventriculostomy (ETV) \& ventriculoperitoneal (VP) shunt.

\section{Data Analysis}

All data was entered in complete SSP version was utilized for data analysis.

\section{RESULTS}

A total of 89 pediatric patients were included in the study that underwent the surgical procedure.

\section{Age Distribution}

The average age at treatment was $23 \pm 39.77$ months. The disease was mostly reported in a very young age group, and therefore the age of presentation was very low. Only a few diseases, like tethered cord syndrome, were presented in 12 years.

\section{Gender Distribution}

There were $48 \%$ male and $52 \%$ female patients.

\section{Incidence of Diseases Variants}

Meningocele (MC) was reported in 10 (11.2\%), Myelomeningocele (MMC) in 42 (47.2\%), Myelomeningocele \& Hydrocephalus (MMC \& HCP) in 11 (12.4\%), Tethered Cord Syndrome (TCS) in 23 (25.8\%) and Diastematomyelia in 3 (3.4\%) patients (Table 1). Figure 1 shows the myelomeningocele with a positive transillumination test. This test comprises of 
illuminating the lesion with a light source and

Table 1: Prevalence of Presenting Symptoms of and Disease Variants.

\begin{tabular}{|c|c|c|c|}
\hline Presenting Symptom & $\begin{array}{l}\text { Frequency \& } \\
\text { Percentage }\end{array}$ & Disease Variant & $\begin{array}{l}\text { Frequency \& } \\
\text { Percentage }\end{array}$ \\
\hline Swelling on Back & 59 (66.3\%) & Meningocele (MC) & $10(11.2 \%)$ \\
\hline Lower Limb Weakness & 17 (19.1\%) & \multirow{2}{*}{$\begin{array}{l}\text { Myelomeningocele (MMC) } \\
\text { Myelomeningocele \& Hydrocephalus } \\
(\mathrm{MMC}+\mathrm{HCP})\end{array}$} & $42(47.2 \%)$ \\
\hline Sphincter Dysfunction & $4(4.5 \%)$ & & 11 (12.4\%) \\
\hline $\begin{array}{ll}\text { - } & \text { Concomitant Congenital } \\
& \text { Malformation (skin stigmata) }\end{array}$ & $5(5.6 \%)$ & \multirow[t]{2}{*}{ Tethered Cord Syndrome (TCS) } & \multirow[t]{2}{*}{$23(25.8 \%)$} \\
\hline - Increased ICP symptoms & $4(4.5 \%)$ & & \\
\hline Total & 89 (100\%) & Diastematomyelia & $3(3.4 \%)$ \\
\hline
\end{tabular}
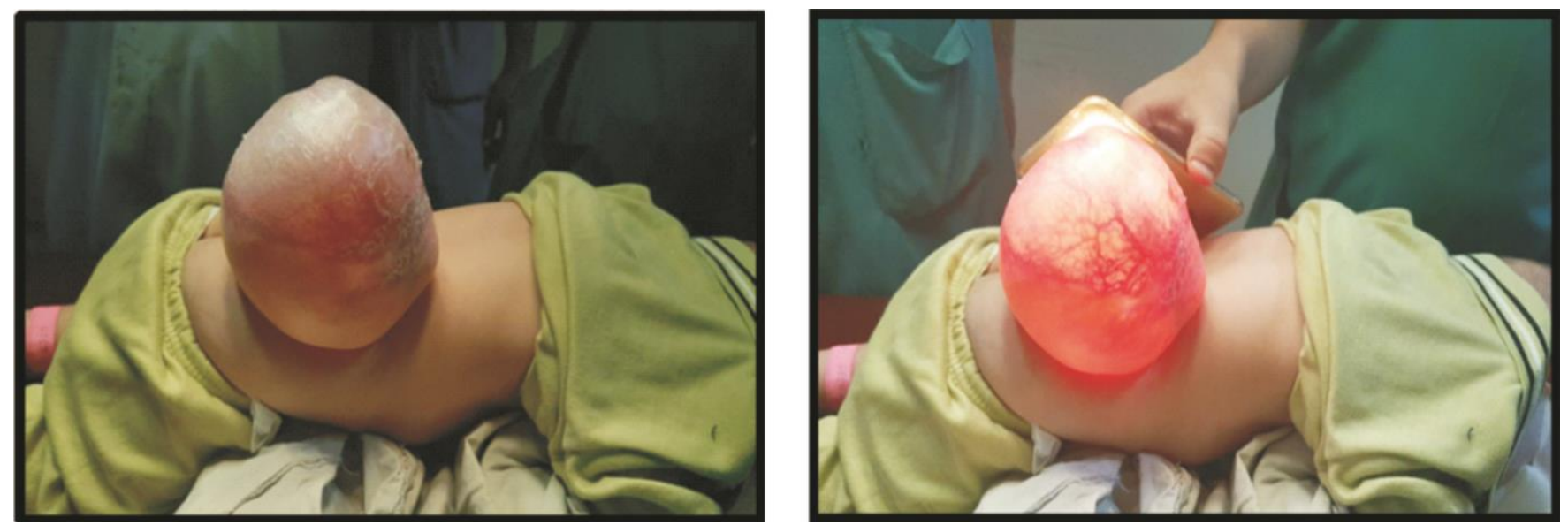

Figure 1: Myelomeningocele with positive transillumination test (included with permission from child's parents).
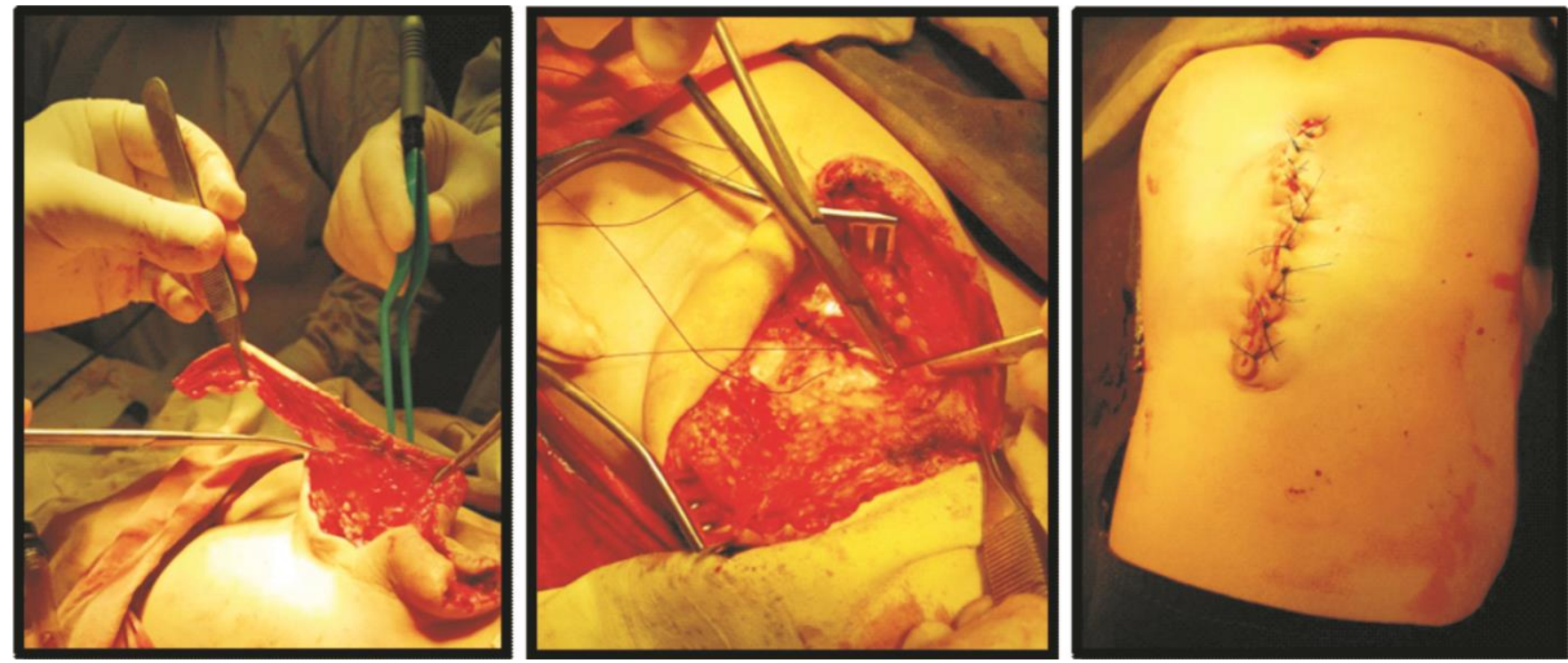

Figure 2: Huge myelomeningocele excised and skin closure via making flap (included with permission from child's parents). 
observing if the lesion illuminates completely or one side of the lesion illuminates. It is performed in dark room and positive in lesions comprising of clear fluid. Figure 2 indicates huge myelomeningocele excised and skin closure via

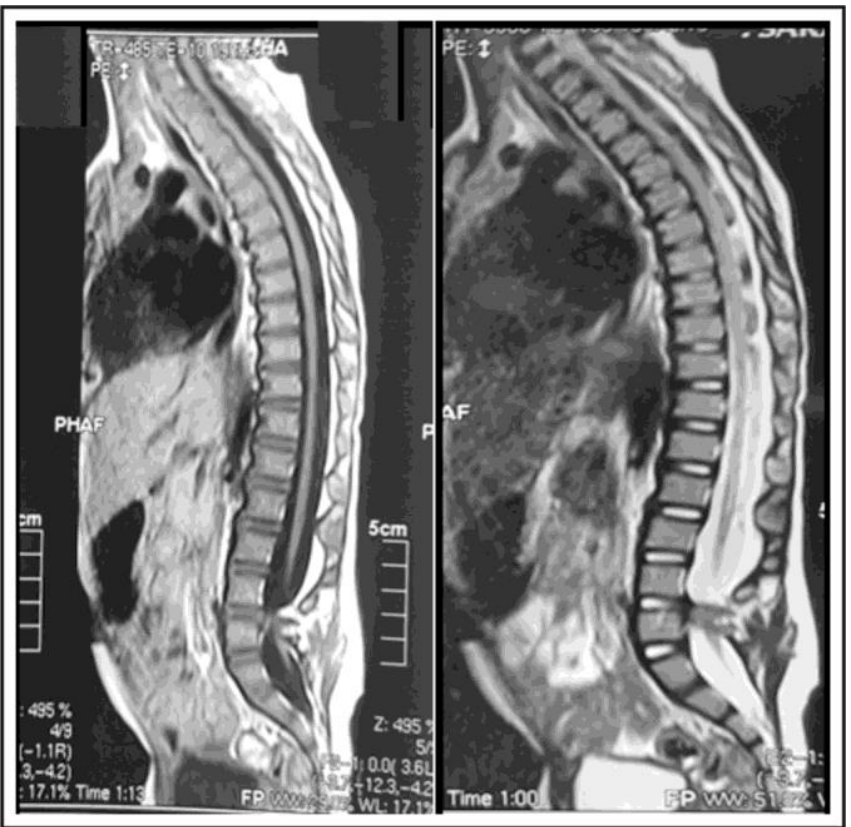

Figure 3: Diastematomyelia Type I, 3a (left): Sagittal T1, 3b (right). Sagittal T2. (included with permission from child's parents)

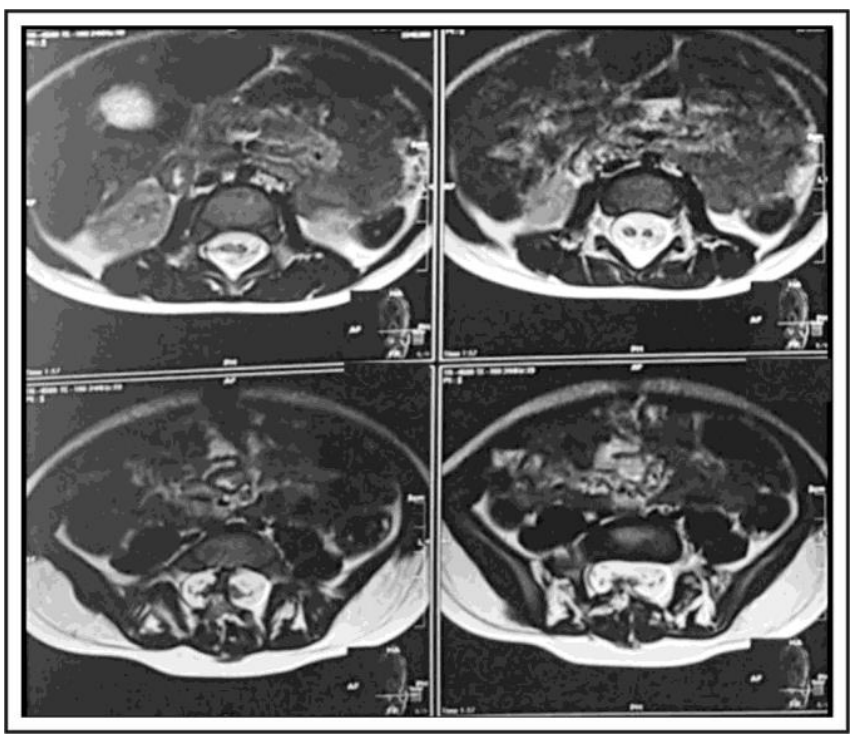

Figure 4: Diastematomyelia Type I, Axial cuts (included with permission from child's parents). making a flap. Figure 3 shows the diastematomyelia Type I with Sagittal T1 and Sagittal T2. Figure 4 shows the Diastematomyelia Type I on axial cuts. Figure 5 and 6 show the diastematomyelia Type 2 with Sagittal T1 \& Sagittal T2. Figures 7 and 8 also show diastematomyelia Type 2. Figure 9 shows a CT brain of a 6 months old baby with triventricular hydrocephalus. Figure 10 shows a baby with myelomeningocele. Figure 11 shows an MRI of 3 months old child operated for myelomeningocele. Figure 12 shows MRI scans of a six months old baby with meningoceles. Figure 13 shows the prevalence of disease variants.

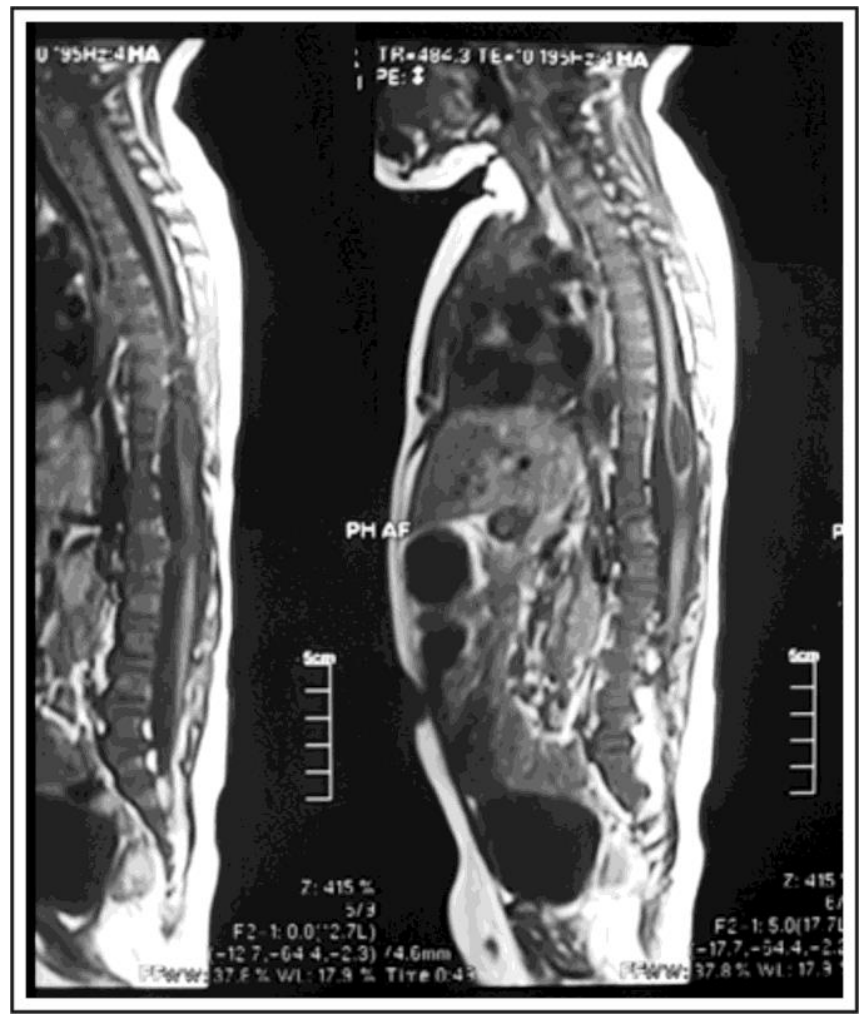

Figure 5: Diastematomyelia Type 2. 5a (left). Sagittal T1, 5b (right). Sagittal T2 (included with permission from child's parents). 


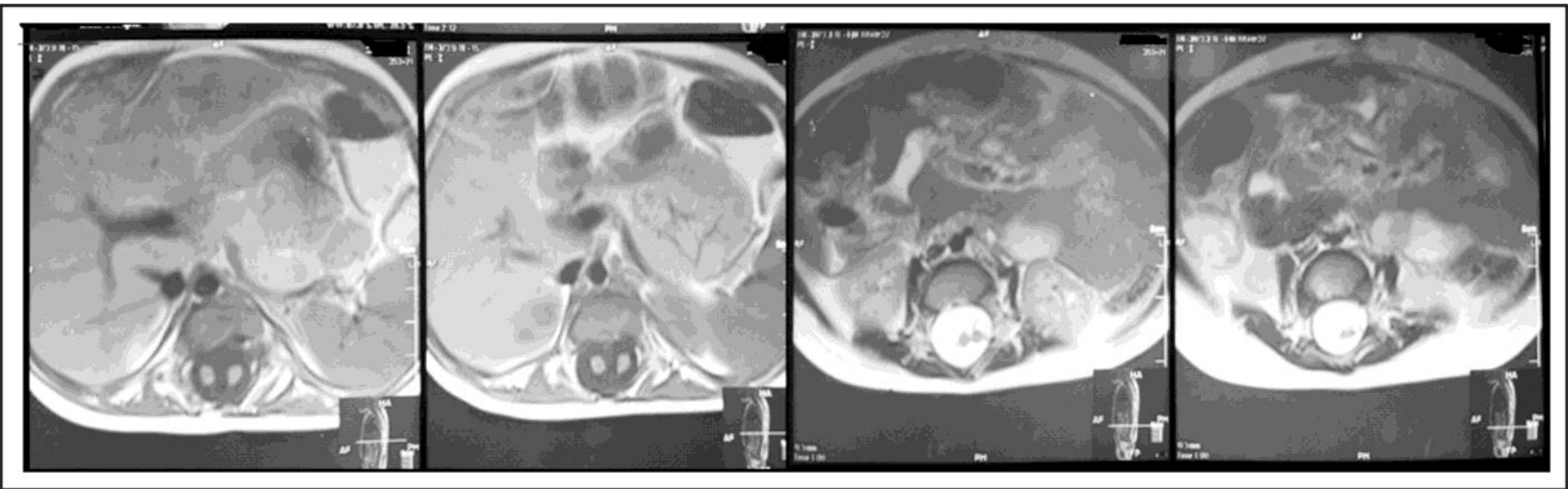

Figure 6: Diastematomyelia Type 2. 6a: Sagittal T1, 6b: Sagittal T2 (included with permission from child's parents).
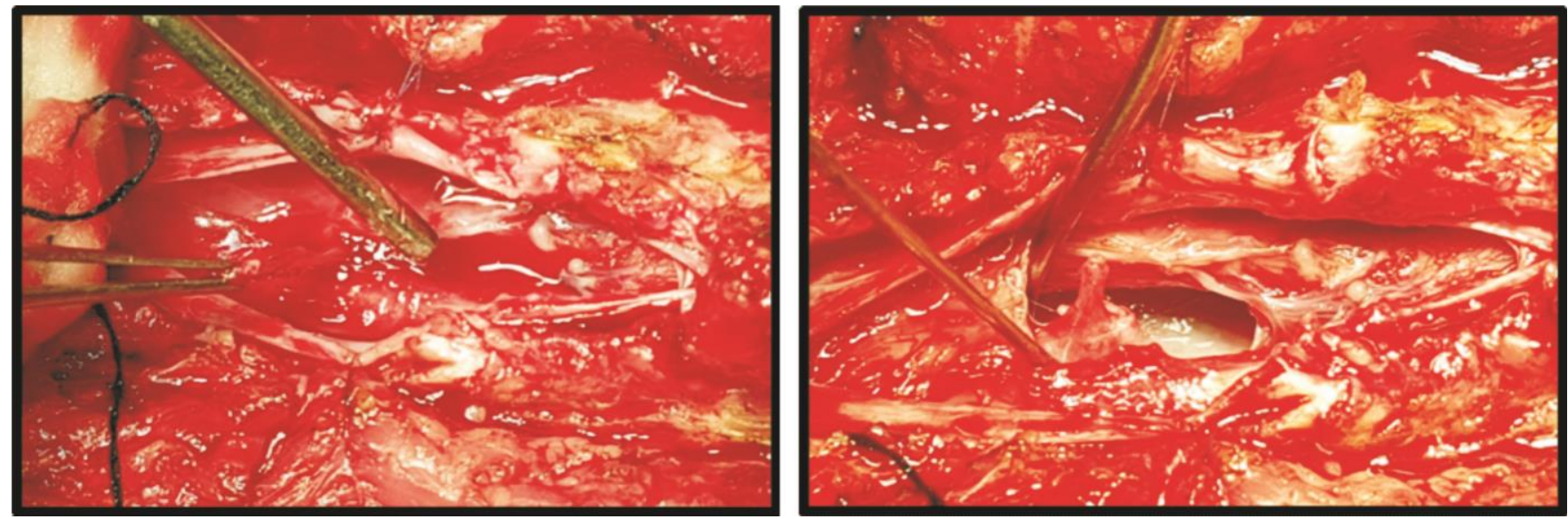

Figure 7: Diastematomyelia Type 2 (included with permission from child's parents).
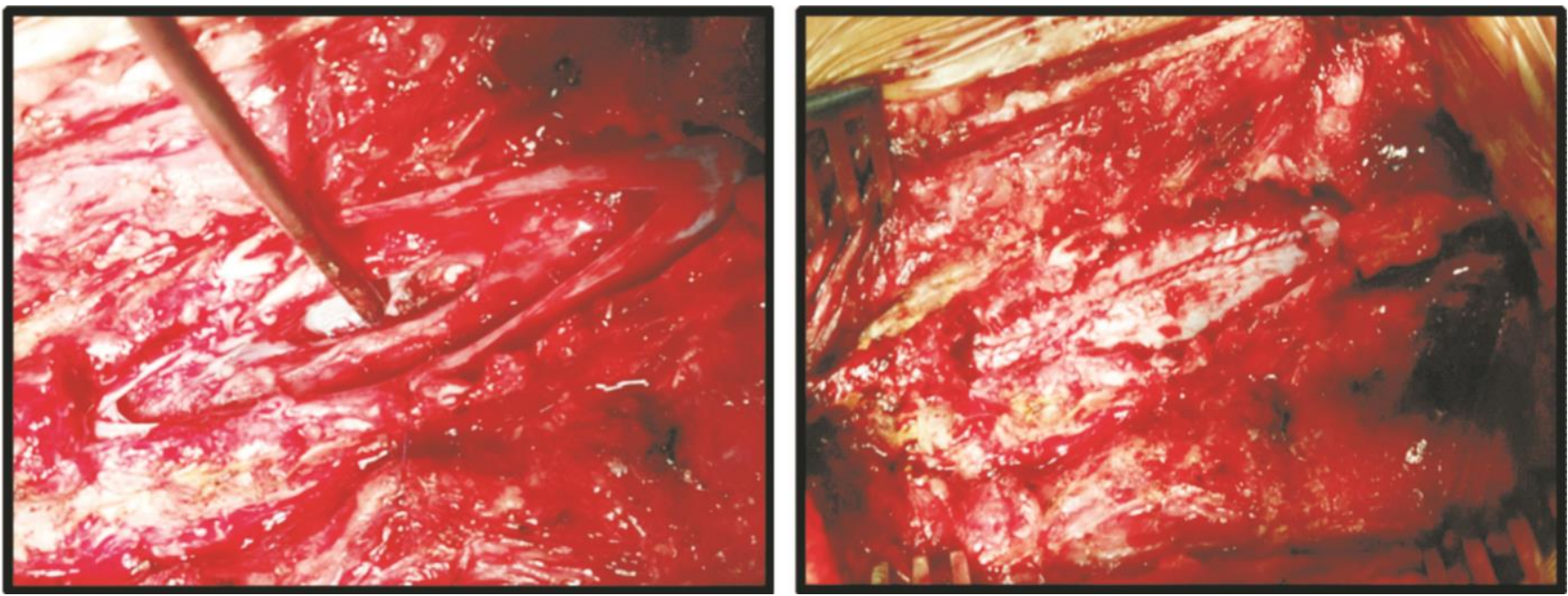

Figure 8: Diastematomyelia Type 2 (included with permission from child's parents). 


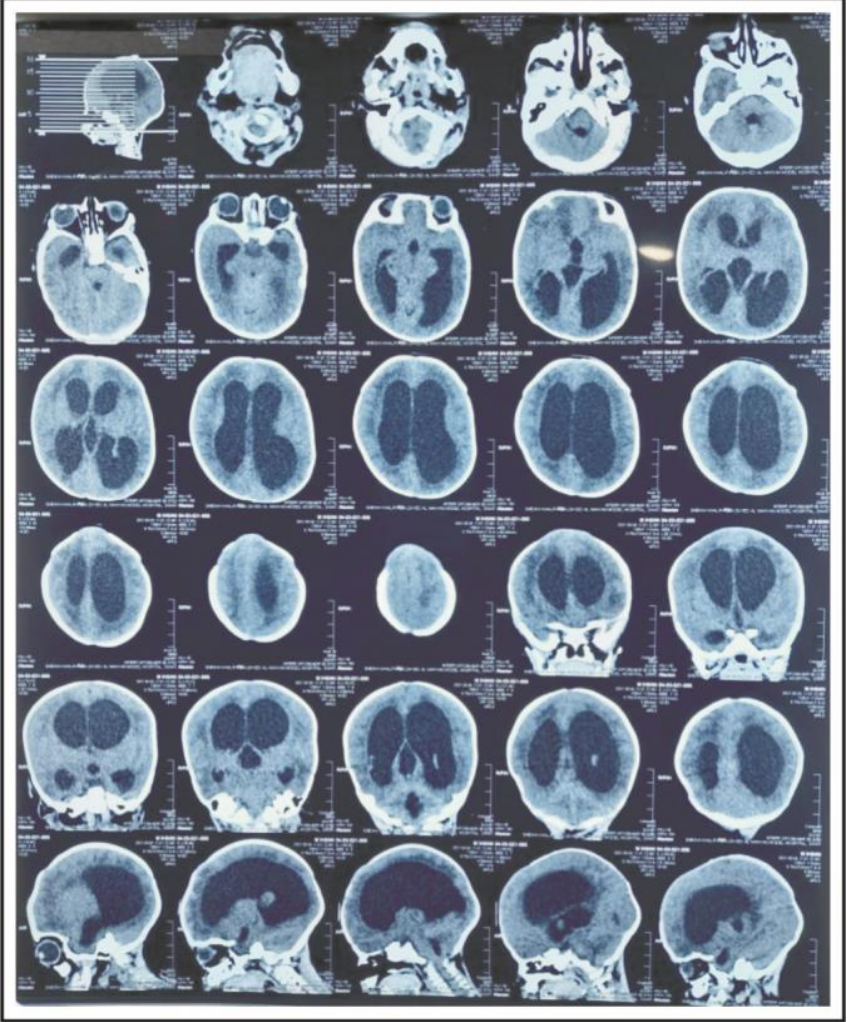

Figure 9: CT brain of a 6 months old baby with triventricular hydrocephalus (included with permission from child's parents).

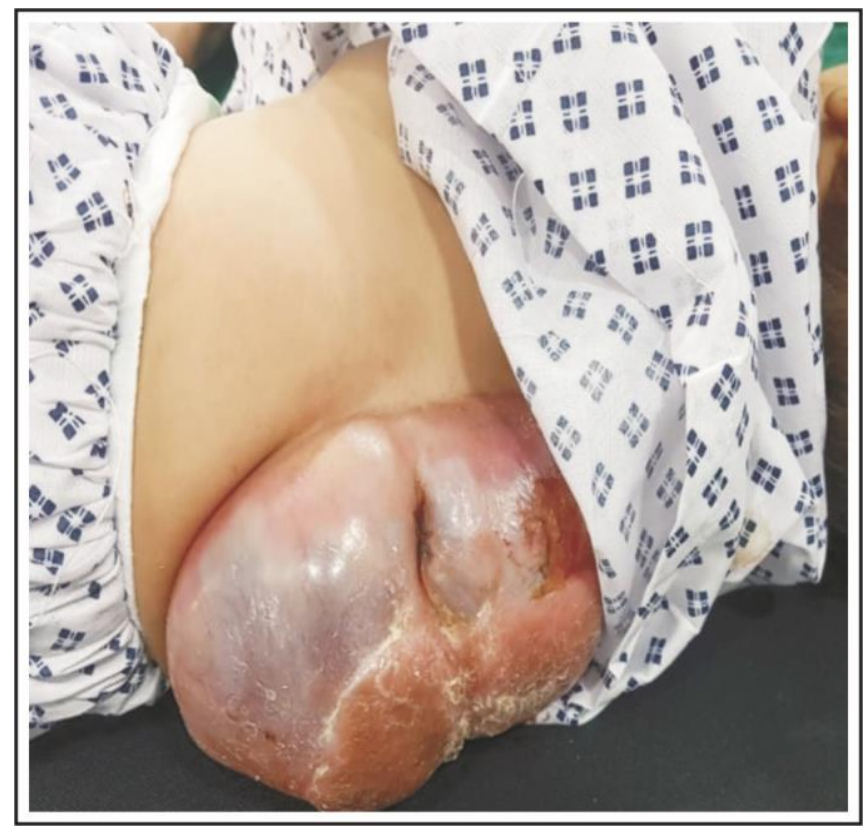

Figure 10: A baby with myelomeningocele (included with permission from child's parents).

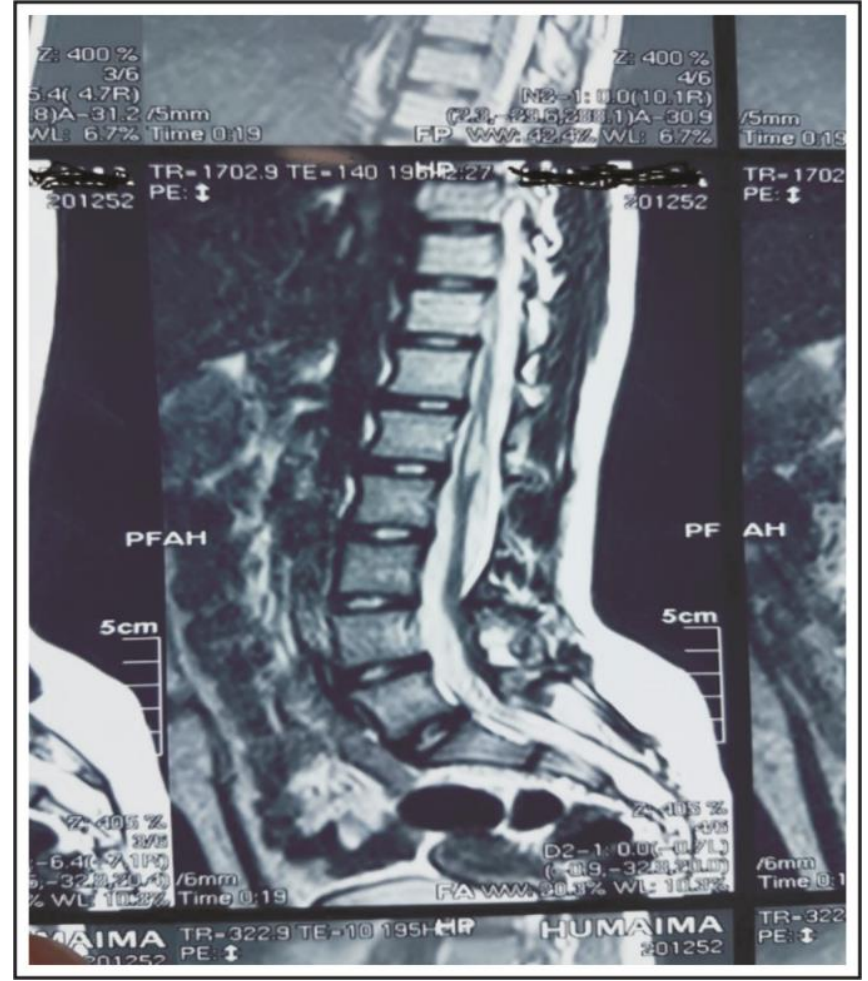

Figure 11: $\mathrm{MRI}$ of 3 months old child operated for myelomeningocele (included with permission from child's parents).

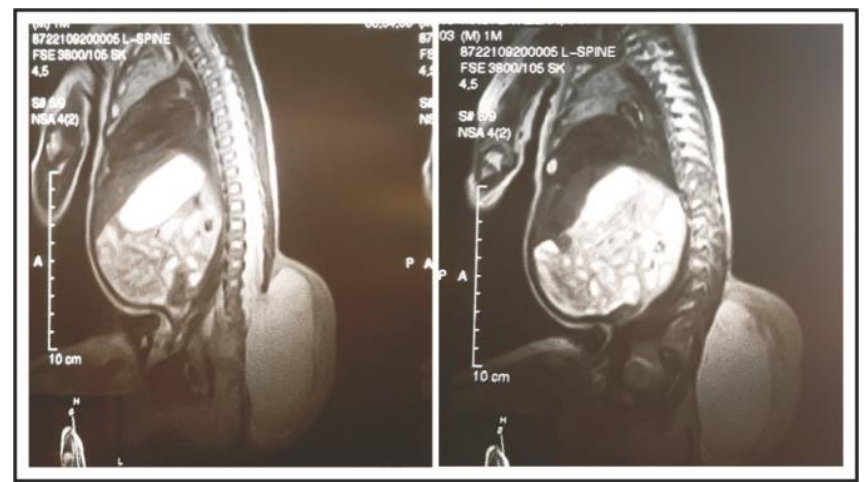

Figure 12: Six months old baby withmeningoceles (included with permission from child's parents).

\section{Presenting Symptoms}

Swelling on the back was reported in 59 (66.3\%), lower limb weakness in 17 (19.1\%), sphincter dysfunction in 4 (4.5\%), symptoms of increased intracranial pressure (ICP) in 4 (4.5\%) and concomitant congenital problems in 5 (5.6\%) 
patients (Table 1). Figure 14 shows the back swelling of patient with meningoceles. Figure 15

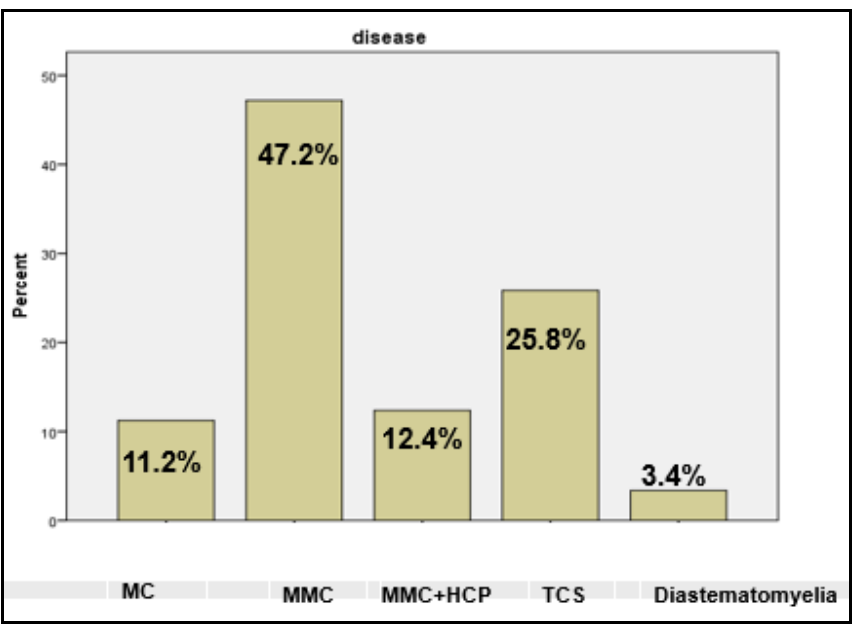

Figure 13: Prevalence of Disease.

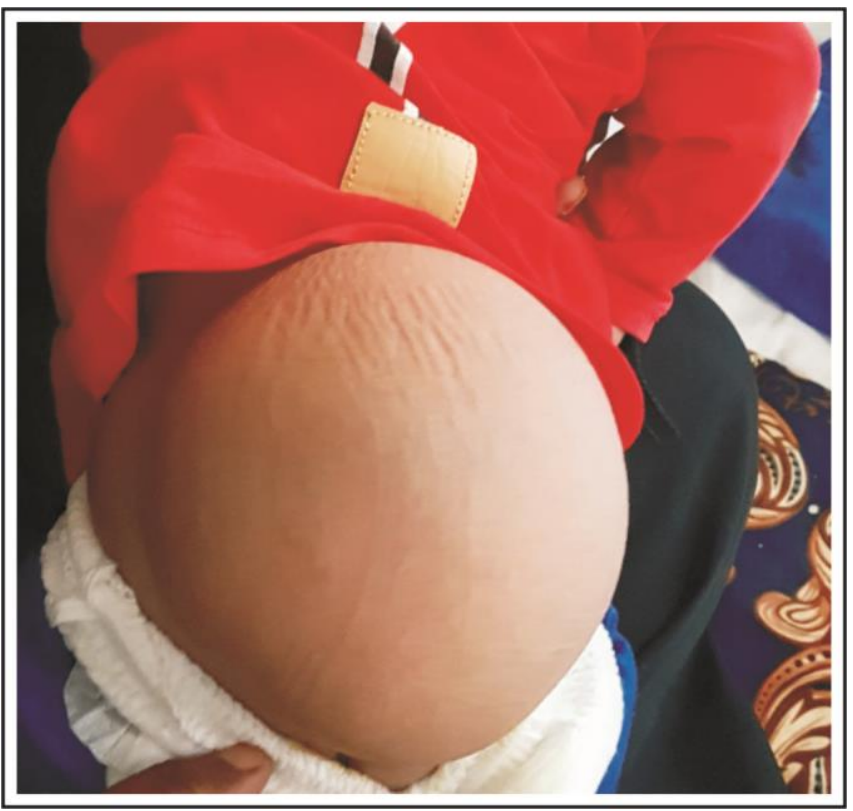

Figure 14: Back swelling of patient with meningoceles (included with permission from child's parents).

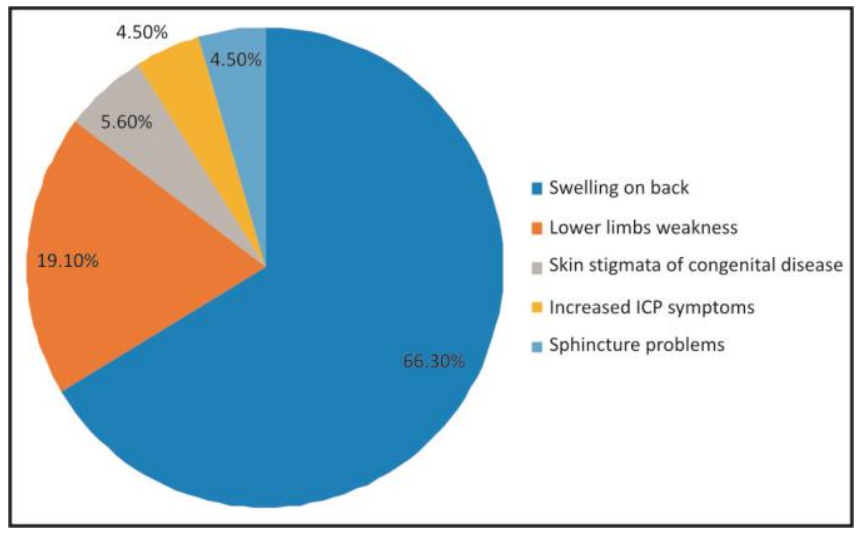

Figure 15: Presenting symptoms in patients.

shows the distribution of presenting symptoms in pie-chart.

\section{Surgical Management}

Excision combined with the repair was done in 52 (58.4\%), release \& repair done in 26 (29.2\%), and Endoscopic Third Ventriculostomy (ETV)/ ventriculoperitoneal (VP) shunts with the repair were done in 11 (12.4\%) patients (Table 2).

\section{Complications}

Cerebrospinal fluid (CSF) leak was reported in 6 (3.7\%), wound infection in 4 (4.5\%) and mortality was reported in 3 (3.4\%) patients (Table 2).

\section{Outcome}

A good outcome was reported in the majority of patients (85.4\%). 14.6\% of patients showed a poor outcome (See Table 2).

Table 2: Treatments Performed and Prevalence's of Complications \& Outcome.

\begin{tabular}{|c|c|c|c|c|c|}
\hline \multicolumn{2}{|c|}{$\begin{array}{c}\text { Treatment Modality } \\
\text { (Frequency \& Percentage) }\end{array}$} & \multicolumn{2}{|c|}{$\begin{array}{c}\text { Complications } \\
\text { (Frequency \& Percentage) }\end{array}$} & \multicolumn{2}{|c|}{$\begin{array}{c}\text { Outcome } \\
\text { (Frequency \& Percentage) }\end{array}$} \\
\hline Excision + Repair & 52 (58.4\%) & CSF Leak & $6(3.7 \%)$ & Good & $76(85.4 \%)$ \\
\hline Release + Repair & $26(29.2 \%)$ & Wound Infection & $4(4.5 \%)$ & & \\
\hline ETVNP Shunt + Repair & $11(12.4 \%)$ & Mortality & $3(3.4 \%)$ & Poor & $13(14.6 \%)$ \\
\hline Total & 89 (100\%) & Total & $13(14.6 \%)$ & Total & 89 (100\%) \\
\hline
\end{tabular}

232 Pak. J. of Neurol. Surg. - $2021-25$ (2): 225-236. http//www.pakjns.org 


\section{DISCUSSION}

Neurosurgery is helpful in lesions like diastematomyelia and spinal dysraphism, as concluded through 40 years of study (between 1947 - 1987) along with an experience with the anomalies. $^{13}$ The current study was aimed to assess the spectrum of spinal dysraphism presenting in pediatric patients of Peshawar, Pakistan. In our study, meningocele was reported in $11.2 \%$, myelomeningocele in $47.2 \%$, myelomeningocele \& hydrocephalus in $12.4 \%$, tethered cord syndrome in $25.8 \%$, and diastematomyelia $3.4 \%$ of patients. The most recurring $(66.3 \%)$ presenting symptom was the swelling on the back followed by lower limb weakness. Other less common symptoms were sphincter dysfunction and concomitant congenital problems. The excision combined with the repair was done in the majority of the patients, followed by release \& repair. The Endoscopic third Ventriculostomy (ETV), ventriculoperitoneal (VP) shunts along with repair were done in $12.4 \%$ of patients. We reported cerebrospinal fluid leak and wound infection as complications in few patients. Mortality was reported in $3.4 \%$ of patients. Overall, a good outcome was reported in the majority of patients. Generally speaking, the morbidity and mortality of Diastematomyelia surgery is very low. ${ }^{14}$ However, following surgery, complications are not uncommon. That include changes or worsening of the neurological status, wound-related issues like dehiscence, leakages of CSF, or infections. Chiari malformation can arise with symptoms. Others include gut-related issues like post-operative ileus, necrotizing enterocolitis, and shunt infections. Post-operative kyphectomy related problems also arise. ${ }^{15}$ Warder $(2001)^{12}$ in his study on spinal dysraphism also notified complications related to operations and anesthesia. Meningitis, leakage of CSF, and cognitive impairment were noticeable ones. The commonest complication after surgery is CSF leak. Wound infection with or without meningitis may develop. Deficits of neurological and urological function may be present. Due to attachment of the spinal cord in tethering, the subsequent releases are associated with increased morbidity. The spinal cord is susceptible to minor injuries and causes neurological disturbances. The release of the tethered cord may not stop ongoing scoliosis. Approximately $20 \%$ of children following tethered cord release exhibit shunt malfunction. ${ }^{8}$

Elmesallamy et $\mathrm{al}^{16}$ reported that all patients either improved or were stable following surgery. They were multiple clinical manifestations. Some controllable complications like cerebrospinal fluid (CSF) leak in $18.6 \%$ and wound infection in $4.7 \%$ were common. Back pain and Urodynamic studies improved in the majority of patients. Microscopic surgery is of value for patients suffering tethered cord syndrome with a low risk of complications. ${ }^{16}$ Kumar and Singh ${ }^{17}$ evaluated the clinical profiles, image findings, and surgical outcomes of 155 cases of spinal dysraphism. Of the total 155 patients, 143 were analyzed prospectively and 12 were observed retrospectively. In all cases of spinal dysraphism, 119 had open spina bifida. Seventy-two percent patients had meningomyelocele, two percent had meningoceles. Myelocystocele was seen in 2\% and split malformation of the cord was present in $19 \%$ of patients. Spina bifida occulta was present in 36 patients. Around $4.5 \%$ patients had dermal sinus. Sixty-five percent of patients had lipomyelomeningocele. Eighteen percent of patients had SCM (complex spina bifida). Out of the total, 32\% patients were having split cord malformation. Twenty-four children with myelomeningocele had the operative scar from their previous spinal surgery. After the detailed history and examination, patients were subjected to craniospinal MRI. The patients were followed for 3 to 4 years (mean value 3.6 years) after surgery.

Kumar and Singh $^{17}$ reported that MMC sac was seen in $57 \%$ of patients which was the commonest symptom occurring in 89 out of 155 
patients. Lower limb weakness of varying degrees was present in $66.5 \%$ and $41 \%$ had atrophy of muscles. Fifty-seven percent of patients had graded sensory loss, thirty-six percent had sphincter involvement, eleven percent had trophic ulcers and 6\%, had lumbago. CSF leak occurred in $33 \%$ of all patients (51), wound infection in $14 \%$ and meningitis in $8 \%$ of patients. These represented the commoner postoperative complications. Post-operative deaths occurred in two cases. Clinical improvement in sphincteric function was seen in $41 \%$ (26 patients). Fifty-nine patients had no change or improvement in their deficits and $4 \%$ developed worsening of symptoms. All of the nine patients with backache were relieved of their painful symptoms with $100 \%$ improvement. A considerable number of patients with open spinal dysraphism also had split cord malformation. Comparing to the Western world, the Indian population had a lower incidence of hydrocephalus (HCP). It has been recommended that the neural axis screening (MRI) followed by a planned surgery, should be performed early in the management. ${ }^{17}$ Agarwal and Sampley ${ }^{5}$ conducted a study and included 27 pediatric patients with dysraphism. The median age was 120 days. Mothers of 15 children did not seek any regular antenatal checkup and only 13 mothers received folic acid supplementation during pregnancy. Fourteen children were delivered at home and 13 were at the hospital. The most common site was the lumbosacral region (67.8\%). Seven patients had rupture of the $\mathrm{sac}$ at the time of presentation, one child had a local infection, and four patients had hydrocephalus (requiring shunt before the surgical repair). Two patients developed hydrocephalus at follow-up, needing shunt surgery. ${ }^{5}$

Different opinions are held on the effectiveness of the therapies for hydrocephalus in under two years old children, namely the ventriculoperitoneal shunt and the endoscopic third Ventriculostomy. ETV remained effective in
$56 \%$ of cases of hydrocephalus in the under 2 years' age group in a study where 97 endoscopic procedures were performed. However, those with anatomical obstruction showed $83 \%$ success. Children should be given the chance of an endoscopic third Ventriculostomy and a shunt implant-free life. ${ }^{18}$ In an Indian study of 81 patients where the pathology was limited to the lumbosacral region. The motor system was involved causing muscle weakness and spasticity. The cutaneous signs were lipoma in $26 \%$, hypertrichosis in 20\%, dermal sinus in $13.4 \%$, midline dimples $7 \%$ were the important cutaneous markers. A quarter of the patients had foot and limb deformities. The most common radiological finding was tethering and splitting of the cord. When the results were analyzed, 43 patients out of a total of 119 patients had improved after surgery. Sensory improvement was noticeable in 20 patients while 18 patients showed noticeable improvement in their motor function. Bladder and sphincter control was regained in fifteen patients. Follow-up was not possible in twelve cases. No neurological improvement was seen in 67 patients after surgery. Motor and sensory impairment worsened in six patients and one patient developed incontinence of urine. Other complications were leakage of CSF (occurring in $8 \%$ cases) and infection of wounds in $6 \%$ cases. A second surgery was required in six patients, including a TR Shunt in 4 patients, flap rotation, duraplasty, and re-exploration in one patient each. ${ }^{19}$

Marreiros et $\mathrm{al}^{20}$ mentioned that in child patients of age up to 14 years, neurosurgical interventions in the form of shunts are often performed. They reported that the surgical ulcers were commonly seen after 12 years of age. Cornette et $\mathrm{al}^{21}$ mentioned that untethering was associated with a symptom-free interval of about 12 months followed by some form of spasticity but generally with a good outcome. Re-tethering did not occur in any of the 12 operated children. They concluded that half the number of children 
born with spinal dysraphism and tethered cord did not develop tethering after surgery and their neurological and bladder dysfunction improved. ${ }^{21}$ Jones et $\mathrm{al}^{22}$ studied 25 patients who were subjected to ETV. Only one patient of age less than 6 months out of 11 showed a successful long-term recovery despite a good initial fenestration procedure. The selection of these patients was based on the larger $3^{\text {rd }}$ ventricular size and slow progression of hydrocephalus. Jones et al, $^{22}$ performed Ventriculostomy for 14 patients and 13 showed success long-term. Heyer Schulte valve with the antisiphon device was used initially followed years later by the $3^{\text {rd }}$ Ventriculostomy. The poor resorptive capability of CSF was the explanation for the difference in the two groups. VP shunted patients to get their absorptive capability back with the passage. ${ }^{22}$

\section{CONCLUSION}

We observed a good clinical outcome in the majority of the patients. Surgical procedures like myelomeningocele's excision \& repair, tethered cord's release \& repair, and ETV/VP shunt in patients with hydrocephalus can lead to satisfactory clinical outcomes.

\section{REFERENCES}

1. Reghunath A, Ghasi RG, Aggarwal A. Unveiling the tale of the tail: an illustration of spinal dysraphisms. Neurosurgical Review, 2019; 7: 1-8.

2. Thompson DN. Spinal dysraphic anomalies; classification, presentation and management. Paediatrics and Child Health, 2014; 24 (10): 431-8.

3. Sweet J, Kalhorn CG. Spinal dysraphism: a review of clinical manifestations and surgical treatment options. In Seminars in Spine Surgery, 2005; 17 (1): 23-29. WB Saunders.

4. Venkataramana NK. Spinal dysraphism. Journal of Pediatric Neurosciences, 2011; 6 (Suppl. 1): S31.

5. Agrawal A, Sampley S. Spinal dysraphism: A challenge continued to be faced by neurosurgeons in developing countries. Asian Journal of Neurosurgery, 2014; 9 (2): 68.
6. Assaad A, Mansy A, Kotb M, Hafez M. Spinal dysraphism: experience with 250 cases operated upon. Child's Nervous System, 1989; 5 (5): 324-9.

7. Acharya UV, Pendharkar $H$, Varma DR, Pruthi $N$, Varadarajan S. Spinal dysraphism illustrated; Embroyology revisited. The Indian Journal of Radiology \& Imaging, 2017; 27 (4): 417.

8. Hudgins RJ, Gilreath CL. Tethered spinal cord following repair of myelomeningocele. Neurosurgical Focus, 2004 Feb. 1; 16 (2): 1-4.

9. Boop FA, Russell A, Chadduck WM. Diagnosis and management of the tethered cord syndrome. The Journal of the Arkansas Medical Society, 1992; 89 (7): 328-31.

10. Hudgins RJ, Gilreath CL. Tethered spinal cord following repair of myelomeningocele. Neurosurgical Focus, 2004; 16 (2): 1-4.

11. Guggisberg D, Hadj-Rabia S, Viney $C$, Bodemer $C$, Brunelle $F$, Zerah $M$, Pierre-Kahn $A$, de Prost $Y$, Hamel-Teillac D. Skin markers of occult spinal dysraphism in children: a review of 54 cases. Archives of Dermatology, 2004; 140 (9): 1109-15.

12. Warder DE. Tethered cord syndrome and occult spinal dysraphism. Neurosurgical Focus, 2001 Jan. 1; 10 (1): 1-9.

13. Gower DJ, Del Curling O, Kelly Jr DL, Alexander Jr E. Diastematomyelia-a 40-year experience. Pediatric Neurosurgery, 1988; 14 (2): 90-6.

14. Rilliet B. Diastematomyelia. In the Spina Bifida, 2008: pp. 487-513. Springer, Milano.

15. Pang D. Surgical complications of open spinal dysraphism. Neurosurgery Clinics of North America, 1995; 6 (2): 243-57.

16. Elmesallamy WA, Taha MM. Surgical management and prognostic factors of spinal metastatic tumors. Egyptian Journal of Neurosurgery, 2020; 35: 1-8.

17. Kumar R, Singh SN. Spinal dysraphism: trends in northern India. Pediatric Neurosurgery, 2003; 38 (3): 133-45.

18. Etus V, Ceylan S. Success of endoscopic third ventriculostomy in children less than 2 years of age. Neurosurgical Review, 2005; 28 (4): 284-8.

19. Jindal A, Mahapatra AK, Kamal R. Spinal dysraphism. The Indian Journal of Pediatrics, 1999; 66 (5): 697-705.

20. Marreiros H, Loff C, Calado E. Osteoporosis in paediatric patients with Spina bifida. The journal of Spinal Cord Medicine, 2012 Jan. 1; 35 (1): 9-21. 
21. Cornette L, Verpoorten C, Lagae L, Van Calenbergh F, Plets $C$, Vereecken R, Casaer P. Tethered cord syndrome in occult spinal dysraphism: timing and outcome of surgical release. Neurology, 1998; 50
(6): 1761-5.

22. Jones RF, Stening WA, Brydon M. Endoscopic third ventriculostomy. Neurosurgery, 1990; 26 (1): 86-92.

\section{Additional Information}

Disclosures: Authors report no conflict of interest.

Ethical Review Board Approval: The study was conformed to the ethical review board requirements.

Human Subjects: Consent was obtained by all patients/participants in this study.

\section{Conflicts of Interest:}

In compliance with the ICMJE uniform disclosure form, all authors declare the following:

Financial Relationships: All authors have declared that they have no financial relationships at present or within the previous three years with any organizations that might have an interest in the submitted work.

Other Relationships: All authors have declared that there are no other relationships or activities that could appear to have influenced the submitted work.

\section{AUTHORS CONTRIBUTIONS}

\begin{tabular}{|l|l|l|}
\hline Sr.\# & Author's Full Name & Intellectual Contribution to Paper in Terms of: \\
\hline 1. & Arif Hussain & Study design and methodology. \\
\hline 2. & Musawer Khan & Paper writing and data calculations. \\
\hline 3. & Arif Hussain & Data collection and calculations. \\
\hline 4. & Huma Gul & Analysis of data and interpretation of results etc. \\
\hline 5. & Musawer Khan & Literature review and referencing. \\
\hline 6. & Ambreen Syed & Analysis of data and quality insurer. \\
\hline
\end{tabular}

